\title{
Avaliação da influência das variáveis açúcar, polvilho azedo e albedo de laranja na elaboração de bolos de chocolate
}

\author{
Evaluation of the influence of the variables sugar, fermented cassava starch \\ and orange albedo in the development of chocolate cakes
}

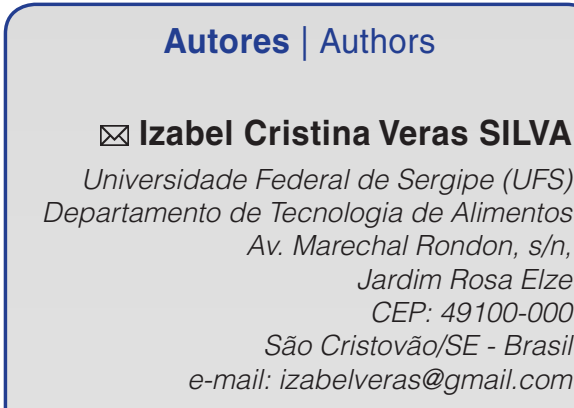

Aline Alves Oliveira SANTOS

Universidade Federal de Sergipe (UFS) Departamento de Tecnologia de Alimentos São Cristovão/SE - Brasil e-mail: alinealimentos@gmail.com

Danielle Gomes SANTANA

Universidade Federal de Sergipe (UFS) Faculdade de Farmácia Departamento de Fisiologia São Cristovão/SE - Brasil e-mail: dani.bioq@hotmail.com

\section{Alécia Josefa Alves Oliveira SANTOS}

Mayara Lúcia da Costa LEITE

Universidade Federal de Sergipe (UFS) Núcleo de Nutrição São Cristovão/SE - Brasil e-mail: alecia_alves@hotmail.com larayam_05@hotmail.com

Meirielly Lima ALMEIDA

Universidade Federal de Sergipe (UFS) Faculdade de Farmácia

Departamento de Fisiologia São Cristovão/SE - Brasil e-mail: meirifarma@hotmail.com

\section{Paulo Sérgio MARCELLINI}

Universidade Federal do Estado do Rio de Janeiro (UNIRIO)

Departamento de Tecnologia de Alimentos Rio de Janeiro/RJ - Brasil

e-mail:marcellinips@yahoo.com

\ Autor Correspondente / Corresponding Author

Recebido / Received: 30/08/2011 Aprovado / Approved: 24/06/2013 Publicado / Published: set./2013

\section{Resumo}

A indústria de alimentos tem demonstrado interesse em fontes alternativas de ingredientes, como o polvilho azedo, um derivado da mandioca, e o subproduto da indústria de suco, albedo de laranja, que vêm agregar valor econômico e nutricional ao produto. O presente trabalho teve como objetivo avaliar a influência da concentração de açúcar, polvilho azedo e albedo de laranja na formulação de um bolo de chocolate. Foram adotadas concentrações delineadas por planejamento fatorial $2^{3}$, tendo como variáveis independentes: polvilho azedo (X, de 14,90 a 40,10 \%), açúcar ( $Y$, de 74,80 a 125,20 \%) e farinha de albedo da laranja (Z, de 4,15 a 8,35\%); como variáveis dependentes, os atributos da análise sensorial, utilizando escala hedônica estruturada de nove pontos. As formulações otimizada, padrão ( 100 \% trigo) e comercial foram avaliadas quanto às características físico-químicas e sensoriais, por meio de teste de aceitação e teste de intenção de compra. Os valores sensoriais apresentaram médias entre 5 (não gostei/nem desgostei) e 8 (gostei muito). As diferentes formulações apresentaram diferenças significativas $(p<0,05)$ em relação aos parâmetros sensoriais e a escolha da formulação ideal foi feita a partir da aceitação em relação à impressão global, sendo significativa a concentração de açúcar e farinha de albedo de laranja. Assim, a formulação otimizada apresentou 27,5\% de polvilho azedo, $130 \%$ de açúcar e $6 \%$ de farinha de albedo de laranja. No teste sensorial comparativo, os bolos apresentaram diferença significativa $(p<0,05)$ para os atributos aparência e aroma. As características físico-químicas dos bolos comercial, padrão e otimizado mostraram influência significativa $(p<0,05)$ para os parâmetros umidade e proteínas.

Palavras-chave: Manihot esculenta; Farinha mista; Testes sensoriais; Fibroenriquecido.

\section{Summary}

The food industry has shown interest in alternative sources of ingredients such as fermented cassava starch derived from cassava, and orange albedo, a byproduct of the juice industry, which aggregate nutritional and economic value to the product. This study aimed to evaluate the influence of the concentrations of sugar, fermented cassava starch and orange albedo in the formulation of a chocolate cake. The concentrations adopted were defined by a $2^{3}$ factorial design, taking as the independent variables: fermented cassava starch (X, from 14.90 to $40.10 \%$ ), sugar ( $Y$, from 74.80 to $125.20 \%$ ) and orange albedo flour (Z, 4.15 to $8.35 \%)$, and the sensory analysis attributes as the dependent variables, using a nine point hedonic scale. The optimized formulation, standard (100\% wheat) and commercial one were evaluated for their physicochemical characteristics, sensory acceptance and purchasing intent. The sensory results showed that the averages were between 5 (neither liked/nor disliked) and 8 (liked a lot). The sensory parameters of the different formulations showed significant differences $(p<0.05)$, and the optimal formulation was chosen according to the overall impression, the sugar and orange albedo flour concentrations being significant. Thus the optimized formulation contained $27.5 \%$ of fermented cassava starch, $6 \%$ orange albedo and $130 \%$ sugar. In the comparative sensory test, the cakes presented significant difference $(p<0.05)$ for the attributes of appearance and aroma. The physicochemical characteristics showed a significant influence $(p<$ 0.05 ) on the parameters of moisture and protein contents. 


\section{Introdução}

A mandioca (Manihot esculenta Crantz) é uma das mais tradicionais culturas brasileiras, cultivada em praticamente todo o território nacional. A produção brasileira de mandioca em 2010 foi de 24.524 .318 toneladas (IBGE, 2010a).

O Brasil é tradicionalmente o pioneiro no aproveitamento industrial da mandioca (LIMA, 2001). Dentre os principais produtos derivados da mandioca, destaca-se o polvilho, que pode ser classificado em doce (fécula de mandioca) ou azedo, tendo por base apenas o teor de acidez (CEREDA, 1987). O polvilho azedo é um produto obtido a partir de uma fermentação após a etapa de decantação da fécula e antes da secagem, que é obrigatoriamente feita por método solar (EMBRAPA, 2007).

$\mathrm{O}$ amido fermentado pode ser adicionado à farinha de trigo em misturas para a obtenção de produtos que não necessitam de farinha forte, como bolos, massa, bolachas, biscoitos de polvilho, pão de queijo (VILELA e FERREIRA, 1987 citado por APLEVICZ, 2006).

A fermentação aumenta o valor nutritivo do amido, ao aumentar a porcentagem de proteínas em relação à mandioca (CARDENAS e BUCKLE, 1980 citado por CARVALHO et al., 1996). Da mesma forma, a fécula fermentada oferece certas características, como sabor, textura e expansão aos produtos panificados (CEREDA, 1987), tornando-se uma alternativa para a substituição parcial da farinha de trigo na elaboração bolos.

A laranja (Citrus sinensis L.) pertence à família das Rutáceas, gênero Citrus, é consumida principalmente "in natura" e na forma de suco, industrializado ou não (SANTANA, 2005). Atualmente, o Brasil é um dos maiores produtores de laranja do mundo, com uma produção de 18.101.708 toneladas em 2010 (IBGE, 2010b).

A indústria de sucos cítricos estima um montante de $15 \times 10^{6}$ toneladas de resíduos, sendo que a quantidade de resíduo obtida a partir do fruto corresponde a $50 \%$ da massa do fruto inteiro (MARín et al., 2007). Esses resíduos são constituídos de casca (flavedo e albedo), membranas carpelares, vesículas de suco e sementes (SANTANA, 2005).

O albedo ou mesocarpo é a parte branca da casca e consiste de células despigmentadas, bem como o núcleo (SANTANA, 2005). Apresenta um teor de pectina de $39,25 \%$ (GONÇALVES et al., 2001) e de fibra total de $76,50 \%$, sendo $60,02 \%$ de fibra insolúvel e $16,48 \%$ de fibra solúvel (SANTANA, 2005), tornando-o um subproduto com um grande potencial na elaboração de produtos panificáveis enriquecidos nutricionalmente.

Inúmeros estudos utilizando resíduos industriais do processamento de alimentos têm sido realizados com objetivo de aproveitamento destes. Com isso, minimiza-se o impacto ambiental desses tipos de indústrias na região onde estão situadas e ainda agrega-se valor aos produtos do mercado (PELIZER et al., 2007).

A viabilidade técnica e econômica da utilização de farinhas mistas na produção de alimentos já foi amplamente demonstrada e empregada na indústria (EL-DASH e GERMANI, 1994). Como exemplo, tem-se o bolo, que é um produto obtido de mistura, homogeneização e cozimento conveniente de massa preparada com farinhas, fermentadas ou não, e outras substâncias alimentícias, como leite, ovos e gorduras (BORGES et al., 2006).

A elaboração de bolos com a substituição parcial da farinha de trigo por outros tipos de farinhas (farinhas mistas) tem sido utilizada por vários autores. Moscatto et al. (2004) avaliaram o uso da farinha mista envolvendo trigo, inulina e yacon; Borges et al. (2006) analisaram a farinha mista com trigo e aveia, e Santos (2008) utilizou farinha mista contendo trigo e casca de maracujá em formulações de bolos de chocolate.

O açúcar é um ingrediente muito questionado na elaboração de produtos alimentícios, principalmente em relação aos efeitos que o seu elevado consumo proporciona ao organismo, causando uma série de patologias, como obesidade, diabetes e cárie dental (MARCELLINI et al., 2006).

Assim, o presente trabalho teve como objetivo estudar o efeito das variáveis açúcar, polvilho azedo e albedo de laranja nas formulações de bolos de chocolate, a fim de oferecer um produto economicamente viável e com melhor qualidade nutricional.

\section{Material e métodos}

A laranja doce (Citrus sinensis Osbeck cv. Pêra), usada na obtenção da farinha de albedo, foi adquirida em feira livre, em Itabaiana-SE. Os demais ingredientes - farinha de trigo, polvilho azedo, achocolatado em pó, açúcar cristal, gordura vegetal, leite em pó, fermento em pó químico, sal, clara de ovo, essência de baunilha e água - foram adquiridos no comércio local da cidade de Aracaju-SE.

Para a produção da farinha de albedo de laranja, utilizou-se a metodologia proposta por Santana (2005). Inicialmente, as laranjas foram lavadas, sanitizadas e descascadas manualmente. Logo após, foi feita a trituração úmida na proporção de 1:5 (albedo:água) em volume. O material foi acondicionado em sacos de algodão e lavado sob água corrente por um período de aproximadamente 30 minutos. A secagem foi realizada em estufa a $100{ }^{\circ} \mathrm{C}$, durante aproximadamente 5 horas. Posteriormente, triturou-se o albedo seco no liquidificador até a obtenção de uma farinha, sendo peneirada em tamis com malha de 500 mesh. O acondicionamento da 
farinha de albedo de laranja se deu em potes plásticos, armazenados em local seco e à temperatura ambiente.

A formulação padrão e o preparo dos bolos seguiram a metodologia proposta por Centenauro et al. (2004), utilizando-se $280 \mathrm{~g}$ de farinha de trigo; $280 \mathrm{~g}$ de açúcar cristal; $100 \mathrm{~g}$ de gordura vegetal; $13 \mathrm{~g}$ de fermento químico; $6 \mathrm{~g}$ de sal; $24 \mathrm{~g}$ de leite em pó; $40 \mathrm{~g}$ de achocolatado em pó; $138 \mathrm{~g}$ de água; $150 \mathrm{~g}$ de clara de ovo, e 6 gotas de essência de baunilha.

Inicialmente, os ingredientes foram pesados em balança semianalítica. Para o preparo do bolo, primeiramente, misturaram-se a gordura vegetal e o açúcar em batedeira (modelo Planetária da marca ARNO), em velocidade média, por 10 minutos. Em seguida, a adição de farinha de trigo, polvilho azedo, farinha de albedo de laranja, achocolatado em pó, leite em pó, sal e fermento químico; por último, adicionaram-se as claras de ovo batidas em ponto de neve, misturando manualmente. A massa foi então colocada em fôrma de alumínio circular com furo no meio (ROCHEDO, n. ${ }^{\circ} 24$ ), previamente untada com gordura vegetal e farinha de trigo, e levada ao forno (Fogão de Piso Sonata CFI76F 4 Bocas Branco - Consul), a $270{ }^{\circ} \mathrm{C}$ por 30 minutos.

$\mathrm{Na}$ elaboração das formulações de bolos de chocolate, foi aplicado um delineamento estatístico em metodologia de superfície de resposta $2^{3}$, com variáveis independentes: as concentrações de polvilho azedo $(X)$, açúcar (Y) e farinha de albedo da laranja (Z) (Tabela 1); como variáveis dependentes, os atributos sensoriais: aparência, aroma, sabor, textura e impressão global.

As variações nos teores de polvilho azedo e farinha de albedo de laranja observadas na Tabela 1 são em relação à concentração de farinha de trigo aplicadas na formulação padrão, sendo que o mesmo comportamento também foi feito para os teores de açúcar.

A avaliação sensorial dos bolos foi realizada em duas etapas. Inicialmente, as formulações elaboradas a partir do planejamento experimental foram analisadas por 50 provadores. O segundo teste, afetivo, foi comparativo entre as formulações: comercial (mistura para bolo), padrão (100 \% trigo) e otimizado (polvilho azedo, farinha de albedo de Iaranja), com 100 provadores. Estes avaliaram, de forma monádica, o quanto gostavam e desgostavam do produto, por meio de um teste de aceitação baseado numa escala hedônica estruturada de nove pontos ( 9 = gostei muitíssimo; 5 = não gostei, nem desgostei; 1 = desgostei muitíssimo) e no teste de intenção de compra, utilizando escala estruturada de sete pontos ( 7 = certamente compraria; 4 = talvez comprasse $/$ talvez não comprasse; 1 = certamente não compraria), conforme descrito por Stone e Sidel (2004).

A caracterização físico-química da farinha de albedo de laranja e das formulações comercial, padrão e otimizado foi realizada segundo metodologia descrita pela AOAC (HORWITZ, 2000) e pelo Instituto Adolfo Lutz (IAL, 2005). As avaliações dos teores de umidade,

Tabela 1. Valores médios da avaliação sensorial dos bolos com incorporação de diferentes teores de polvilho azedo, açúcar e farinha de albedo de laranja.

\begin{tabular}{|c|c|c|c|c|c|c|c|c|}
\hline \multirow{2}{*}{ Ensaio } & \multicolumn{3}{|c|}{ Variáveis Codificadas* } & \multicolumn{5}{|c|}{ Atributos } \\
\hline & $\mathbf{x}$ & $\mathbf{Y}$ & z & Aparência & Aroma & Sabor & Textura & Impressão global \\
\hline 1 & $20 \%$ & $85 \%$ & $5 \%$ & 7,16 & 7,18 & 7,42 & 7,36 & 7,32 \\
\hline 2 & $20 \%$ & $85 \%$ & $7,50 \%$ & 6,78 & 6,50 & 6,52 & 6,46 & 6,52 \\
\hline 3 & $20 \%$ & $115 \%$ & $5 \%$ & 7,68 & 7,60 & 7,72 & 7,56 & 7,56 \\
\hline 4 & $20 \%$ & $115 \%$ & $7,50 \%$ & 7,28 & 7,10 & 7,32 & 7,22 & 7,26 \\
\hline 5 & $35 \%$ & $85 \%$ & $5 \%$ & 6,96 & 7,18 & 7,16 & 6,86 & 7,14 \\
\hline 6 & $35 \%$ & $85 \%$ & $7,50 \%$ & 6,92 & 6,92 & 6,94 & 6,78 & 6,92 \\
\hline 7 & $35 \%$ & $115 \%$ & $5 \%$ & 7,02 & 7,52 & 7,64 & 6,62 & 7,42 \\
\hline 8 & $35 \%$ & $115 \%$ & $7,50 \%$ & 7,46 & 7,46 & 7,16 & 7,00 & 7,22 \\
\hline 9 & $14,90 \%$ & $100 \%$ & $6,25 \%$ & 7,20 & 7,46 & 7,78 & 7,68 & 7,66 \\
\hline 10 & $40,10 \%$ & $100 \%$ & $6,25 \%$ & 6,74 & 6,92 & 6,88 & 5,52 & 6,86 \\
\hline 11 & $27,50 \%$ & $74,80 \%$ & $6,25 \%$ & 7,08 & 6,92 & 6,96 & 6,94 & 7,00 \\
\hline 12 & $27,50 \%$ & $125,20 \%$ & $6,25 \%$ & 7,88 & 7,66 & 8,14 & 7,92 & 7,84 \\
\hline 13 & $27,50 \%$ & $100 \%$ & $4,15 \%$ & 7,20 & 7,48 & 7,50 & 7,64 & 7,60 \\
\hline 14 & $27,50 \%$ & $100 \%$ & $8,35 \%$ & 5,94 & 6,42 & 6,38 & 5,78 & 6,32 \\
\hline 15 & $27,50 \%$ & $100 \%$ & $6,25 \%$ & 6,90 & 6,68 & 7,02 & 6,74 & 7,02 \\
\hline 16 & $27,50 \%$ & $100 \%$ & $6,25 \%$ & 6,94 & 7,24 & 7,52 & 7,10 & 7,18 \\
\hline 17 & $27,50 \%$ & $100 \%$ & $6,25 \%$ & 6,94 & 7,02 & 7,12 & 7,00 & 7,02 \\
\hline 18 & $27,50 \%$ & $100 \%$ & $6,25 \%$ & 6,80 & 6,92 & 6,88 & 6,62 & 6,76 \\
\hline
\end{tabular}

*X - concentração de polvilho azedo; Y - concentração de açúcar, em relação à concentração da formulação padrão, 280 g; Z - concentração de farinha de albedo de laranja. 
lipídeos, cinzas e proteínas foram realizadas em triplicata. O teor de fibra bruta foi feito em duplicata. O teor de carboidratos foi determinado por diferença entre a massa seca total (100 \%) e a soma das porcentagens dos teores de umidade, cinzas, proteínas, lipídeos e fibra bruta. O valor calórico (kcal/100g) foi calculado pela soma dos resultados da multiplicação dos fatores gerais de conversão para lipídeos e para carboidratos e proteínas, sendo $9 \mathrm{kcal} / \mathrm{g}$ e $4 \mathrm{kcal} / \mathrm{g}$, respectivamente, de acordo com o disposto na RDC n. ${ }^{\circ}$ 360/03 da ANVISA (BRASIL, 2003).

As concentrações ótimas foram definidas por meio do planejamento fatorial, com os cálculos de ANOVA e os coeficientes de determinação obtidos a partir do programa Statistic/Windows 8.0. Os resultados físicoquímicos e os testes afetivos foram submetidos à Análise de Variância (ANOVA) e as médias, comparadas pelo teste de Tukey $(p<0,05)$, utilizando o programa Assistat/ Windows 7.5 .

\section{Resultados e discussão}

A farinha de albedo de laranja apresentou características favoráveis à elaboração de novos produtos, com teor de umidade $4,82 \%$, cinzas $4,29 \%$, proteínas 3,15\%, lipídeos 0,39\%, fibra bruta 39,15\%, carboidratos 48,20 \% e valor calórico 208,91 kcal/100g.

\subsection{Análise sensorial}

Os resultados das médias das notas da avaliação sensorial (Tabela 1) demonstram que os bolos elaborados obtiveram médias, para todos os atributos, entre 5,52 e 8,14, o que corresponde, na escala hedônica, aos termos "não gostei/nem desgostei" e "gostei muito", respectivamente, comprovando que a substituição parcial da farinha de trigo por polvilho azedo e farinha de albedo de laranja é uma alternativa na elaboração de bolos.

No atributo aparência, as médias sensoriais variaram entre 5,94 e 7,88 (Tabela 1), referentes a "não gostei nem desgostei" e a "gostei moderadamente". A maior nota de avaliação sensorial $(7,88)$ correspondeu ao ensaio com maior teor do ingrediente açúcar (Ensaio 12). A aparência dos bolos está relacionada, principalmente, com a cor. Esteller et al. (2006) afirmam que a cor é um parâmetro crítico em produtos forneados. Bolos com crostas muito claras ou muito escuras estão associados a falhas no processo de formulação. Segundo Giese (2000), a presença de açúcares e ovos na formulação, assim como o calor, acelera reações de caramelização e de Maillard, levando ao escurecimento progressivo da crosta e do miolo, o que pode ser desejado ou não.

$\mathrm{O}$ atributo aroma apresentou as médias entre 6,42 e 7,66 (Tabela 1), que correspondem a "gostei ligeiramente" e a "gostei moderadamente", respectivamente.
O atributo sabor obteve notas de 6,38 a 8,14 (Tabela 1), referentes a "gostei ligeiramente" e a "gostei muito", respectivamente, na escala hedônica. O gosto doce apresenta uma alta aceitação entre os consumidores, como se mostra nas médias sensoriais das formulações 3, 4, 7, 8 e 12, com maior concentração de açúcar em sua composição, que apresentaram notas de sabor maiores, em relação às demais amostras, de 7,72; 7,$32 ; 7,64 ; 7,16$ e 8,14 , respectivamente.

No atributo textura, as formulações com maior teor de açúcar obtiveram as melhores médias, com destaque para a formulação com 125 \% de açúcar em relação ao padrão (100 \%), que apresentou a maior média $(7,92)$ (Tabela 1). O acréscimo de mais de $30 \%$ de açúcar à receita básica, que já continha $100 \%$, tornou a massa mais viscosa e os bolos maiores, mais macios e aveludados. No entanto, os bolos com nível elevado de açúcar apresentaram tendência a encolher durante o assamento, proporcionando o aparecimento de uma camada compacta na região inferior do bolo. Os bolos com menor concentração de açúcar apresentaram contorno mais arredondado do que aqueles com concentrações elevadas (GRISWOLD, 1972).

No entanto, a formulação que apresentou o maior teor de substituição da farinha de trigo por farinha de albedo de laranja (8,35 \%) obteve a menor média sensorial para textura $(5,78)$ (Tabela 1$)$, conforme descrito por uma parcela de $10 \%$ dos provadores, que relataram um aspecto de textura "ligada". Descrição coerente com Esteller et al. (2006), segundo a qual a adição de fibras, amido e açúcar pode promover um maior crescimento na parte superior e deixar a massa úmida e compacta na parte inferior, apresentando uma aparência "embatumada".

Em relação à impressão global, os bolos apresentaram médias sensoriais entre 6,32 e 7,84 (Tabela 1), entre "gostei ligeiramente" e "gostei moderadamente", respectivamente.

A Tabela 2 apresenta os valores de $p$ para os atributos sensoriais do teste de ANOVA, no nível de $5 \%$ de probabilidade, para os bolos elaborados com polvilho azedo e farinha de albedo de laranja.

Analisando-se os valores de $p$ para os atributos aparência e aroma (Tabela 2), notou-se um efeito significativo $(p<0,05)$ para os constituintes açúcar e farinha de albedo de laranja, mostrando que os provadores perceberam as alterações nos níveis de concentração destes, aplicadas no teste sensorial. O planejamento explicou $83 \%$ para a característica aparência e 60 \% para o atributo aroma.

Para o parâmetro sabor, as concentrações variadas de açúcar e farinha de albedo de laranja adotadas nas formulações podem ser perceptíveis pelos provadores, o que demonstra que as mesmas sofreram influência significativa no nível de $5 \%$, com valor de $p$ de 0,0057 
Avaliação da influência das variáveis açúcar, polvilho azedo e albedo de laranja na elaboração de bolos de chocolate SILVA, I. C. V. et al.

e 0,0050 (Tabela 2), respectivamente, com um nível de explicação de $82 \%$.

As variáveis polvilho azedo e farinha de albedo de laranja apresentaram diferença significativa no atributo textura, com valores de $p<0,05$ (Tabela 2), demonstrando que os diferentes níveis de concentração aplicados aos mesmos no experimento foram percebidos pelo painel sensorial, com uma explicação de $75 \%$ das variações dos dados experimentais.

Para a impressão global, os constituintes açúcar e farinha de albedo de laranja apresentaram efeito significativo $(p<0,05)$ (Tabela 2$)$, demonstrando que as diferenças nas suas concentrações puderam ser explicadas pelas variações das médias sensoriais, que explicou $83 \%$ da variabilidade das respostas entre os

Tabela 2. Valores de $p$ para os atributos sensoriais dos bolos com incorporação de polvilho azedo, açúcar e farinha de albedo de laranja.

\begin{tabular}{lccccc} 
Variáveis & \multicolumn{3}{c}{ Valores de $p$ para os atributos sensoriais } \\
& Aparência & Aroma & Sabor & Textura & $\begin{array}{c}\text { Impressão } \\
\text { global }\end{array}$ \\
\hline PA(L) & 0,1870 & 0,8135 & 0,1547 & 0,0178 & 0,1775 \\
PA(Q) & 0,4284 & 0,2220 & 0,4677 & 0,5504 & 0,2601 \\
AR(L) & 0,0115 & 0,0060 & 0,0057 & 0,1607 & 0,0098 \\
AR(Q) & 0,0088 & 0,0982 & 0,1144 & 0,1310 & 0,0739 \\
FA(L) & 0,0252 & 0,0048 & 0,0050 & 0,0412 & 0,0031 \\
FA(Q) & 0,2609 & 0,9909 & 0,3344 & 0,7587 & 0,7217 \\
PA $\times$ AR & 0,5632 & 0,8350 & 0,6200 & 0,4663 & 0,5700 \\
PA $\times$ FA & 0,1287 & 0,2228 & 0,4614 & 0,2637 & 0,3434 \\
AR $\times$ FA & 0,5275 & 0,5753 & 0,7649 & 0,4489 & 0,4634 \\
$\mathbf{R}^{2}$ & 0,83 & 0,60 & 0,82 & 0,75 & 0,83 \\
\hline PA
\end{tabular}

$\mathrm{PA}=$ polvilho azedo; $\mathrm{AR}$ = acúcar; $F \mathrm{~A}$ = farinha de albedo de laranja; $\mathrm{L}$ = fator linear; $\mathrm{Q}$ = fator quadrático; $\mathrm{R}^{2}$ = coeficiente de determinação. provadores. De acordo com Meilgaard et al. (1999), pode-se inferir a preferência dos consumidores em função dos valores relativos de aceitabilidade obtidos nos testes afetivos, ou seja, as amostras com maiores notas serão as preferidas pelos julgadores. Desse modo, neste trabalho, considerou-se como adequada a região dos modelos de superfície referentes às maiores notas dos atributos sensoriais avaliados. A partir das superfícies de resposta e dos demais resultados obtidos, foi escolhida uma região otimizada com os melhores níveis de concentração, visando-se a ter um produto com "alto teor de fibras", segundo a Legislação Brasileira, e com propriedades físico-químicas adequadas.

\subsection{Ponto ótimo}

A escolha das concentrações pode ser explicada a partir dos gráficos de superfície de resposta adotada para o atributo impressão global (Figura 1), uma vez que esse parâmetro representa a soma de todas as características sensoriais analisadas.

A Figura 1 apresenta o gráfico de superfície de resposta em relação à concentração de açúcar e à concentração de farinha de albedo de laranja para o atributo impressão global, com a concentração de polvilho azedo fixo em 27,5 \%. Observou-se que a região de maior aceitação apresentou uma variação entre 120 e 130 \% para a concentração de açúcar, em relação à formulação padrão (100 \% açúcar), e o teor de farinha de albedo de laranja na faixa de 3,5 a $8 \%$.

A concentração de polvilho azedo escolhida foi de 27,5 \%, com objetivo de agregar valor econômico a produtos derivados da mandioca.

Vale ressaltar que os níveis de substituição máximos adotados neste planejamento para o polvilho
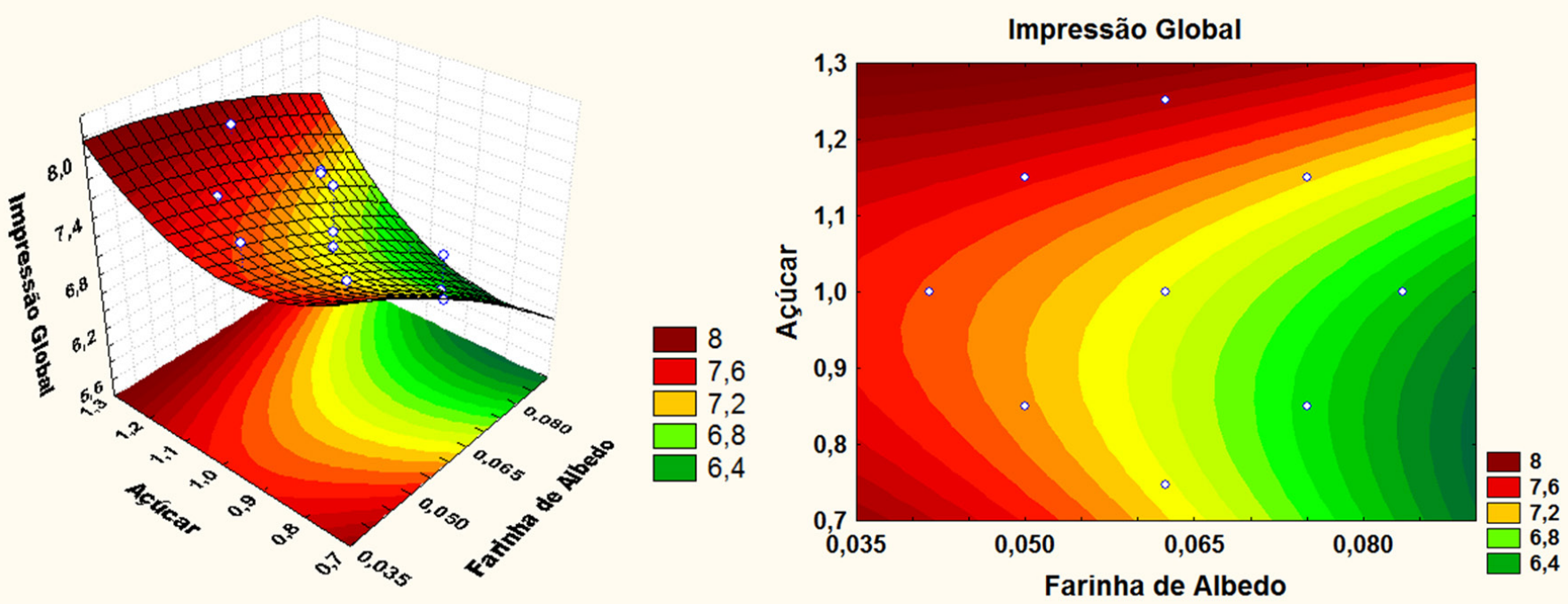

Figura 1. Superfície de resposta e curvas de contorno para impressão global em função das concentrações de açúcar e farinha de albedo de laranja. 
azedo e para farinha de albedo de laranja, de 40,1\% e $8,35 \%$, respectivamente, deixaram o bolo "embatumado", com a textura compactada, apresentando um aspecto desagradável ao provador, como pode ser evidenciado pelas menores médias de aceitação atribuídas à textura, nos ensaios $10(5,52)$ e $14(5,78)$ (Tabela 1), respectivamente.

A concentração escolhida de açúcar foi de 130 \%, levando em consideração a percepção distinta de apreciação da doçura das regiões brasileiras (SANTOS et al., 2010), que associam o gosto doce ao produto de melhor qualidade, estando relacionado ao prazer característico que esse ingrediente confere aos produtos. Tal fato pode ser observado pela maior média de aceitação de 8,14 (Ensaio 12) (Tabela 1) para o parâmetro sabor, atribuída à formulação com maior nível de substituição de açúcar, de 125,20 \%

Conforme El-Dash e Germani (1994), a adição de açúcar no preparo de produtos panificados favorece uma maior retenção da quantidade de líquidos em detrimento a uma redução da proporção de ar, além de ter efeito amaciador. Do contrário, a sua retirada altera a retenção de umidade e reduz o sabor adocicado característico (BENASSI e WATANABE, 1997).

A formulação otimizada escolhida foi de 27,5\% de polvilho azedo, $6 \%$ de farinha de albedo de laranja e 130 \% de açúcar em relação à formulação padrão (100 \% açúcar). Essas concentrações possibilitam uma valorização e a utilização de duas culturas nacionais, a mandioca e a laranja, através de subprodutos, o polvilho azedo e o albedo de laranja, que vêm contribuir para agregar valor econômico e nutricional ao bolo convencional, não prejudicando a aceitabilidade do mesmo.

\subsection{Comparação de bolos comercial, padrão e otimizado}

A Tabela 3 apresenta as médias das notas do teste de aceitação dos atributos sensoriais e do teste de intenção de compra, para os bolos comercial (mistura para bolo), padrão (100 \% trigo) e otimizado (27,5 \% de polvilho azedo, $6 \%$ farinha de albedo de laranja, $130 \%$ de açúcar).

De acordo com a Tabela 3, as amostras comercial, padrão e otimizada não apresentaram diferença significativa entre si nos atributos sabor, textura e impressão global, com médias de aceitação na região de "gostei ligeiramente", "gostei ligeiramente a gostei moderadamente" e "gostei ligeiramente", respectivamente.

Em relação aos atributos aparência e aroma (Tabela 3), observou-se que a amostra padrão não diferiu significativamente das demais amostras, apresentando nota de 6,83 - "gostei ligeiramente" para a aparência, e 6,52 - "gostei ligeiramente" para o aroma. As formulações comercial e otimizada diferiram $(p<0,05)$ entre si, fato este que pode ser explicado em razão de a formulação comercial apresentar-se mais homogênea, diferente da otimizada, na qual foi possível observar a presença de pequenas partículas, provavelmente a farinha de albedo de laranja (Figura 2).

Para o teste de intenção de compra (Tabela 3), observou-se que as notas situaram-se na faixa de "talvez

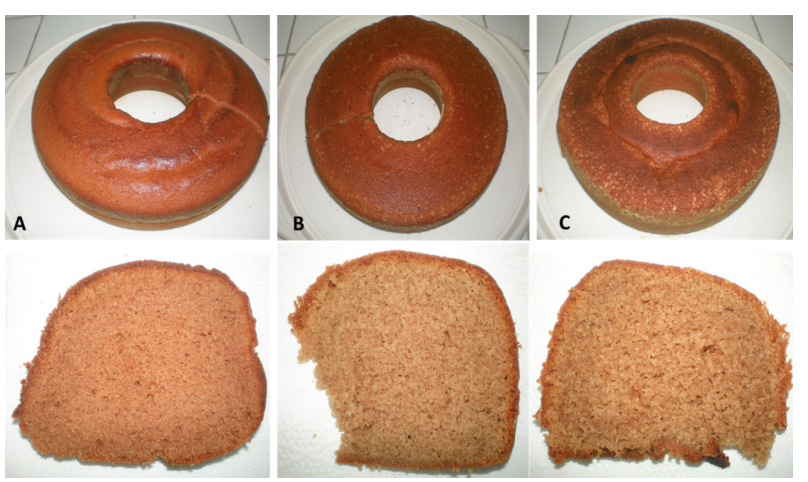

Figura 2. Aparência dos bolos: (A) comercial (mistura para bolo), (B) padrão (100\% trigo) e (C) otimizado $(27,5 \%$ de polvilho azedo, $6 \%$ farinha de albedo de laranja, $130 \%$ de açúcar).

Tabela 3. Médias das notas de aceitação e intenção de compra para os bolos comercial (mistura para bolo), padrão (100 \% trigo) e otimizado (27,5\% de polvilho azedo, $6 \%$ farinha de albedo de laranja, $130 \%$ de açúcar).

\begin{tabular}{|c|c|c|c|}
\hline \multirow{2}{*}{ Atributos sensoriais } & \multicolumn{3}{|c|}{ Formulações } \\
\hline & Comercial & Padrão & Otimizado \\
\hline Aparência & $7,15^{\mathrm{a} 1}$ & $6,83^{\mathrm{ab}}$ & $6,64^{\mathrm{b}}$ \\
\hline Aroma & $6,90^{\mathrm{a}}$ & $6,52^{\mathrm{ab}}$ & $6,19^{b}$ \\
\hline Sabor & $6,45^{a}$ & $6,84^{\mathrm{a}}$ & $6,80^{\mathrm{a}}$ \\
\hline Textura & $6,99^{a}$ & $7,11^{\mathrm{a}}$ & $6,69^{a}$ \\
\hline Impressão global & $6,83^{a}$ & $6,98^{a}$ & $6,67^{a}$ \\
\hline Intenção de compra & $4,85^{\mathrm{a}}$ & $5,20^{a}$ & $4,82^{\mathrm{a}}$ \\
\hline \% de aprovação (notas > 4) & 53 & 65 & 54 \\
\hline \% de rejeição (notas < 4) & 15 & 11 & 19 \\
\hline
\end{tabular}

'Médias seguidas pelas mesmas letras, na mesma linha, não diferem estatisticamente entre si, pelo teste de Tukey a 5 \% de probabilidade. 
Avaliação da influência das variáveis açúcar, polvilho azedo e albedo de laranja na elaboração de bolos de chocolate SILVA, I. C. V. et al.

Tabela 4. Resultados das análises físico-químicas dos bolos comercial (mistura para bolo), padrão (100 \% trigo) e otimizado (27,5\% de polvilho azedo, $6 \%$ farinha de albedo de laranja, $130 \%$ de açúcar).

\begin{tabular}{|c|c|c|c|}
\hline \multirow{2}{*}{ Parâmetros } & \multicolumn{3}{|c|}{ Formulações } \\
\hline & Comercial & Padrão & Otimizado \\
\hline Umidade (\%) & $26,32^{\mathrm{a} 2}$ & $21,49^{b}$ & $16,89^{c}$ \\
\hline Cinzas (\%) & $1,78^{a}$ & $1,72^{\mathrm{ab}}$ & $1,47^{b}$ \\
\hline Proteínas (\%) & $7,26^{a}$ & $5,09^{b}$ & $4,14^{c}$ \\
\hline Lipídios (\%) & $10,77^{a}$ & $11,37^{a}$ & $10,25^{a}$ \\
\hline Fibra bruta (\%) & & 1,03 & 1,79 \\
\hline Fibra alimentar ${ }^{1}(\%)$ & 2,19 & & \\
\hline Carboidratos (\%) & 51,65 & 59,30 & 65,44 \\
\hline Energia (kcal/100g) & 332,57 & 359,96 & 370,63 \\
\hline
\end{tabular}

Valor declarado no rótulo do bolo; 'Letras iguais na mesma linha indicam não haver diferença significativa entre as médias pelo teste de Tukey a $5 \%$ de probabilidade.

comprasse, talvez não comprasse", com notas de 4,85; 5,20 e 4,82, para as amostras comercial, padrão e otimizada, respectivamente.

Em relação à porcentagem de aprovação e rejeição (Tabela 3), as formulações apresentaram índices de aprovação superiores a 50 \% e, para os índices de rejeição, valores de 11 \% (padrão), 15 \% (comercial) e $19 \%$ (otimizado), todos abaixo de $20 \%$, indicando que menos de um quinto dos provadores rejeitou as formulações.

\subsection{Caracterização físico-química dos bolos}

A Tabela 4 apresenta os resultados das análises físico-químicas para os bolos comercial (mistura para bolo), padrão (100 \% trigo) e otimizado $(27,5 \%$ de polvilho azedo, 6 \% farinha de albedo de laranja, $130 \%$ de açúcar).

O teor de umidade (Tabela 4) das amostras diferiu significativamente $(p<0,05)$. A formulação comercial apresentou maior teor de umidade (26,32 \%) (Tabela 4) em relação às demais amostras, o que está de acordo com o teor descrito por Jooste (1951) citado por Esteller et al. (2006), de 30 \% para bolos industrializados. Umidade em excesso aumenta a atividade microbiana e deixa as massas "grudentas" (ESTELLER et al., 2006). Em relação ao teor de cinzas (Tabela 4), o bolo otimizado apresentou o menor valor $(1,47)$ e não diferiu estatisticamente do bolo padrão, porém diferiu estatisticamente em relação ao bolo comercial, que obteve o maior resultado $(1,78)$.

O teor de proteínas diferiu significativamente no nível de $5 \%$ entre as amostras. O bolo comercial obteve o maior valor, com 7,26 \% (Tabela 4), seguido dos bolos padrão e otimizado. A redução do teor de proteínas na formulação otimizada pode ser atribuída à substituição parcial da farinha de trigo por polvilho azedo. Segundo a TACO (UNICAMP, 2006), o trigo apresenta aproximadamente 9,8 \% de proteínas, sendo 1,5\% para o polvilho azedo (MARCON et al., 2007).
O teor de lipídios (Tabela 4) não diferiu significativamente entre as amostras de bolos, tendo a amostra padrão maior teor (11,37\%), seguida do bolo comercial $(10,77)$ e do bolo otimizado $(10,25 \%)$.

Quanto ao teor de fibra bruta (Tabela 4), o bolo otimizado apresentou um maior teor, de 1,79\%, em relação ao padrão (1,03 \%), o que mostra que a farinha de albedo de laranja agregou uma parcela de fibras ao produto desenvolvido. Entretanto, o bolo desenvolvido não pode ser classificado como "fonte de fibras", de acordo com a Legislação Brasileira (BRASIL, 1998).

A concentração da farinha de albedo de laranja escolhida foi de $6 \%$, com o propósito de desenvolver um bolo rico em fibras, respeitando a Legislação Brasileira que descreve dois termos para a rotulagem referente ao teor de fibras: "fonte de fibras" ou "alto teor de fibras". O primeiro enunciado equivale a um valor mínimo de $3 \mathrm{~g}$ de fibras em cada $100 \mathrm{~g}$ de produto sólido, enquanto que o segundo equivale a um valor mínimo de $6 \mathrm{~g}$ de fibras em cada $100 \mathrm{~g}$ de produto sólido (BRASIL, 1998).

O teor de carboidratos (Tabela 4) variou de 51,65\% (comercial) a 65,44 \% (otimizado). O aumento do teor na amostra otimizada em comparação com o padrão pode estar associado ao teor de carboidratos presente no polvilho azedo de 95,6 \% (MARCON et al., 2007), que é maior que o teor presente na farinha de trigo, de $75,1 \%$ (UNICAMP, 2006).

O valor energético (Tabela 4) das amostras variou de $332,57 \mathrm{kcal} / 100 \mathrm{~g}$ (comercial) a $370,73 \mathrm{kcal} / 100 \mathrm{~g}$ (otimizado).

\section{Conclusões}

A região otimizada para os bolos com polvilho azedo e farinha de albedo de laranja foi de 27,5\% de polvilho azedo, $6 \%$ de farinha de albedo de laranja e 130 \% de açúcar, assegurando a valorização e a utilização de produtos nacionais, a mandioca e a laranja, por meio da aplicação do polvilho azedo e da farinha de albedo de laranja. 
Avaliação da influência das variáveis açúcar, polvilho azedo e albedo de laranja na elaboração de bolos de chocolate SILVA, I. C. V. et al.

A substituição parcial da farinha de trigo por polvilho azedo e farinha de albedo de laranja na elaboração dos bolos de chocolate é uma alternativa promissora, visto que esse produto apresentou boas características sensoriais, não prejudicando a aceitabilidade do mesmo.

\section{Referências}

APLEVICZ, K. S. Caracterização de Produtos Panificados à Base de Féculas de Mandioca Nativas e Modificadas. 2006. $131 \mathrm{f}$. Dissertação (Mestrado em Ciência e Tecnologia de Alimentos)Universidade Estadual de Ponta Grossa, Ponta Grossa, 2006.

BENASSI, T. V.; WATANABE, E. Fundamentos da Tecnologia e Panificação. Rio de Janeiro: Embrapa Agroindústria de Alimentos, 1997. 60 p. (Embrapa Agroindústria de Alimentos. Boletim Técnico, n. 21).

BORGES, J. T. S.; PIROZI, M. R.; LUCIA, S. M. D.; PEREIRA, P. C.; MORAES, A. R. F.; CASTRO, V. C. Utilização de farinha mista de aveia e trigo na elaboração de bolos. Boletim do CEPPA, Curitiba, v. 24, n. 1, p. 145-162, 2006.

BRASIL. Ministério da Saúde. Portaria $n^{\circ} 27$, de 13 de janeiro de 1998. Aprova o regulamento técnico referente à informação nutricional complementar (declarações relacionadas ao conteúdo de nutrientes). Diário Oficial da República Federativa do Brasil, Brasília, DF, 16 jan. 1988. Seção 1. Disponível em: <http://e-legis.bvs.br/leisref/public/showAct.php> Acesso em 04 dez. 2009.

BRASIL. Ministério da Saúde. Agência Nacional de Vigilância Sanitária. Resolução - RDC n 360 de 23 de dezembro de 2003. Aprova o regulamento técnico sobre rotulagem nutricional de alimentos embalados, tornando obrigatória a rotulagem nutricional. Diário Oficial da República Federativa do Brasil, Brasília, DF, 26 dez. 2003. Seção 1. Disponível em: <http://www. anvisa.gov.br/legis/resol/2003/rdc/360_03rdc.htm>. Acesso em: 30 set. 2012.

CARVALHO, E. P.; CANHOS, V. P.; RIBEIRO, V. E.; CARVALHO, H. P. Polvilho azedo: aspectos físicos, químicos e microbiológicos. Pesquisa Agropecuária Brasileira, Brasília, v. 31, n. 2 , p. 129-137, fev. 1996.

CENTENAURO, G. S.; FEDDERN, V.; MORAES, K. S.; ZAVAREZE, E. R.; SALASMELLADO, M. Elaboração de produtos de panificação enriquecidos com subprodutos da industria de alimentos. In: CONGRESSO BRASILEIRO DE CIÊNCIA E TECNOLOGIA DE ALIMENTOS, 19., 2004, Recife. Anais... Recife: SBCTA, 2004. 1 CD-ROM.

CEREDA, M. P. Tecnologia e Qualidade do Polvilho Azedo. Informe Agropecuário, Belo Horizonte, v. 13, n. 145, p. 63-68, 1987.

EL-DASH, A.; GERMANI, R.. Tecnologia de Farinhas Mistas: Uso de Farinhas Mistas na Produção de Bolos. Brasília: Embrapa, 1994. v. 7, p. 31.
EMBRAPA. Produtos da Fécula de Mandioca é Tema do Prosa Rural. Brasília: Embrapa, 2007. Disponível em: <http://www.embrapa.br/embrapa/imprensa/noticias/2007/ julho/foldernoticia.2007-07-05.5605721790/noticia.2007-0711.3772688973>. Acesso em: 28 nov. 2008.

ESTELLER, M. S.; ZANCANARO JÚNIOR, O.; LANNE, S. C. S. Bolo de "chocolate" produzido com pó de cupuaçu e kefir. Revista Brasileira de Ciências Farmacêuticas, São Paulo, v. 42, n. 3, p. 447-454, 2006. http://dx.doi.org/10.1590/S151693322006000300014

GIESE, J. Color measurement in foods as a quality parameter. Food Technology, Chicago, v. 54, n. 2, p. 62-63, 2000.

GONÇALVES, L. C.; FILIZOLA, R. G.; CONCEIÇÃO, M. L.; SILVA, C. C. M.; ANDRADE, Y. O. Reciclagem das cascas da laranja pêra na produção de suplemento alimentar de fibras solúveis (pectina). In: CONGRESSO BRASILEIRO DE ENGENHARIA SANITÁRIA E AMBIENTAL, 21., 2001, João Pessoa. Anais.. Rio de Janeiro: ABES, 2001. Disponível em: <http://www.bvsde. paho.org/bvsaidis/resisoli/brasil/iii-131.pdf>. Acesso em: 30 set. 2012

GRISWOLD, R. M. Estudo Experimental dos Alimentos. São Paulo: Editora da Universidade de São Paulo, 1972. 469 p.

HORWITZ, W. (Ed.). Official Methods of Analysis of the Association of Official Analytical Chemists. 17th ed. Gaithersburg: AOAC, 2000. 1 CD-ROM.

INSTITUTO ADOLFO LUTZ - IAL. Normas Analíticas do Instituto Adolfo Lutz: Métodos Químicos e Físicos para Análises de Alimentos. 4. ed. Brasília: Ministério da Saúde, 2005. v. 1, 1018 p

INSTITUTO BRASILEIRO DE GEOGRAFIA E ESTATÍSTICA - IBGE. Produção Agrícola Municipal. Informações sobre Culturas Temporárias. Rio de Janeiro: IBGE, 2010 a. Disponível em: <http://www.sidra.ibge.gov.br/bda/tabela/listabl. asp?c $=1612 \& z=p \& o=33>$. Acesso em: 29 set. 2012.

INSTITUTO BRASILEIRO DE GEOGRAFIA E ESTATÍSTICA - IBGE. Produção Agrícola Municipal. Informações sobre Culturas Permanentes. Rio de Janeiro: IBGE, 2010b. Disponível em: <http://www.sidra.ibge.gov.br/bda/tabela/listabl. asp?c $=1613 \& z=p \& o=33>$. Acesso em: 29 set. 2012.

LIMA, J. W. C. Análise Ambiental: Processo Produtivo de Polvilho em Indústrias do Extremo Sul de Santa Catarina. 2001. 149 f. Dissertação (Mestrado em Engenharia de Produção)-Universidade Federal de Santa Catarina, Florianópolis, 2001

MARCELLINI, P. S.; DELIZA, R.; BOLINI, H. M. A. Caracterização sensorial de suco de abacaxi concentrado, reconstituído e adoçado com diferentes edulcorantes e sacarose. Alimentos e Nutrição, Araraquara, v. 17, n. 2, p. 143-150, 2006. 
Avaliação da influência das variáveis açúcar, polvilho azedo e albedo de laranja na elaboração de bolos de chocolate SILVA, I. C. V. et al.

MARCON, M. J. A.; AVANCINI, S. R. P.; AMANTE, E. R. Propriedades Químicas e Tecnológicas do Amido de Mandioca e do Polvilho Azedo. Florianópolis: UFSC, 2007. 101 p.

MARÍN, F. R.; SOLER-RIVAS, C.; BENAVENTE-GARCÍA, O.; CASTILLO, J.; PÉREZ-ALVAREZ, J. A. By-products from different citrus processes as a source of customized functional fibres. Food Chemistry, London, v. 100, p. 736-741, 2007. http://dx.doi. org/10.1016/j.foodchem.2005.04.040

MEILGAARD, M.; CIVILLE, G. V.; CARR, B. T. Sensory Evaluation Techniques. 3rd ed. New York: Boca Raton, 1999. 390 p.

MOSCATTO, J. A.; PRUDÊNCIO-FERREIRA, S. H.; HAULY, M. C. O. Farinha de yacon e inulina como ingredientes na formulação de bolo de chocolate. Ciência e Tecnologia de Alimentos, Campinas, v. 24, n. 4, p. 634-640, 2004. http://dx.doi. org/10.1590/S0101-20612004000400026

PELIZER, L. H.; PONTIERI, M. H.; MORAES, I. O. Utilização de resíduos agro-industriais em processos biotecnológicos como perspectiva de redução do impacto ambiental. Journal of Tecnology Management \& Inovation, Santiago, v. 2, n. 1, p. 118-127, 2007.
SANTANA, M. F. S. Caracterização Físico-química de Fibra Alimentar de Laranja e Maracujá. 2005. 188 f. Tese (Doutorado em Engenharia de Alimentos)-Faculdade de Engenharia de Alimentos, Universidade Estadual de Campinas, Campinas, 2005.

SANTOS, A. V. Obtenção e Incorporação de Farinha de Casca de Maracujá na Produção de Bolos de Chocolate. 2008. 105 f. Dissertação (Mestrado em Engenharia de Processo)Universidade Tiradentes, Aracaju, 2008.

SANTOS, A. A. O.; SANTOS, A. J. A. O.; SILVA, I. C. V.; LEITE, M. L. C.; SOARES, S. M.; MARCELLINI, P. S. Desenvolvimento de biscoitos de chocolate a partir da incorporação de fécula de mandioca e albedo de laranja. Alimentos e Nutrição, Araraquara, v. 21, n. 3, p. 469-480, 2010.

STONE, H.; SIDEL, J. Sensory Evaluation Practices. 3nd ed. Academic Press: New York. 2004. 377 p.

UNIVERSIDADE ESTADUAL DE CAMPINAS - UNICAMP. Tabela Brasileira de Composição de Alimentos - TACO. versão 2. 2. ed. Campinas: UNICAMP/NEPA, 2006. Disponível em: <http://www.unicamp.br/nepa/taco/contar/taco_versao2. pdf $>$. Acesso em: 26 nov. 2009. 